\title{
The value of preoperative diagnostic tests in acute appendicitis, retrospective analysis of 196 patients
}

\author{
Kemal Memisoglu, Bora Karip*, Metin Mestan, Ender Onur
}

\begin{abstract}
Background: In this study our aim was to evaluate the diagnostic value of preoperative laboratory and radiological studies for appendicitis.

Methods: The clinical data of 196 patients who have undergone conventional appendectomy between March 2007 and April 2008 were collected retrospectively. Patients were examined for age, sex, white blood cell count, ultrasonography results, histopathological diagnosis and hospital stay.

Results: Negative appendectomy rate was $17.3 \%$ (27\% for female, $11.5 \%$ for male). White blood cell counts were found to be high in $83 \%$ for acute appendicitis group and \%61 for negative appendectomy group. There were 66 (34\%) patients who had negative USG findings for acute appendicitis. Of these patients, histopathological examination revealed acute appendicitis in 46 patients whereas 20 patients had normal appendix. Hospital stays were $2.79+/-1.9$ and $2.66+/-1.7$ days for negative and positive appendicectomies respectively.

Conclusions: Besides the improvement of diagnostic tests for acute appendicitis, we could not sufficiently reduce the negative appendectomy rate.
\end{abstract}

\section{Background}

Appendicectomy is still the most common procedure in general surgery practice but diagnostic failure may still occur and this leads to delay in treatment or negative (non-therapeutic) appendectomies. We aimed to analyze retrospectively the diagnostic efficiency of the preoperative tests in relation with histopathologic results.

\section{Methods}

Data of the 277 conventional appendectomies performed for acute appendicitis (AA) between March 2007 and April 2008 were collected. Fifteen patients with perforated appendicitis, 23 patients whose preoperative laboratory tests performed at another centre and 43 patients operated on without preoperative ultrasonography (USG) were excluded. In the remaining 196 patients, all had clinical findings such as, history of anorexia, pain followed by nausea, right lower quadrant

\footnotetext{
* Correspondence: borakarip@gmail.com

General Surgery Department, Fatih Sultan Mehmet Training and Research Hospital, E-5, Bostanci, Istanbul, Turkey
}

pain, vomiting, rebound tenderness, guarding, rigidity and conventional appendectomies were carried out. A radiologist performed a graded compression USG (Siemens Sonoline G50) with a $3.5 \mathrm{MHz}$ convex and 7.5 $\mathrm{MHz}$ linear probe. Data for age, sex, white blood cell count, abdominal USG results, histological findings and hospital stay were collected. White blood cell count, higher than $10500 / \mathrm{mm}^{3}$ was accepted as leukocytosis. Primary criterion for diagnosing AA by USG was the evidence of a non-compressible appendix and a measured diameter of greater than $7 \mathrm{~mm}$. Other supporting criteria were echogenic periappendiceal mesenteric/ omental fat, peri-appendiceal fluid collection and mesenteric lymphadenopathy. USG results including one of these were added positive USG for AA group. Criteria of histological acute appendicitis accepted as infiltration of the muscularis propria with polymorphonuclear cells. Pathology results as -appendix vermicularis- without any additional finding were accepted as negative appendectomy (NA). White blood cell counts, USG findings, hospital stay were compared between AA and NA group. All statistical analysis were performed using SPSS for 
Windows (version 15.0). P-values less than 0.05 were accepted as significant.

\section{Results}

In this study we presented 122 male $(62.2 \%)$ and 74 female (37.8\%) patients with median 27 years old (range 7-81 years) respectively. White blood cell counts were found to be high $\left(>10500 / \mathrm{mm}^{3}\right)$ in $80 \%$ while it was $83 \%$ for AA group and \%61 for NA group ( $p>0.05$ ). There were 66 (34\%) patients who had no USG findings for acute appendicitis. Of these, 46 (70\%) patients were observed to have histologically proved AA. There were 130 patients who had positive USG findings for AA and $11 \%$ of these had histologically normal appendix.

Negative appendectomy rate (NAR) was $17.3 \%$; this rate was $11.5 \%$ for male and $\% 27$ for female patients $(\mathrm{p}=0,003)$ (Table 1$)$. Negative appendectomy rate (NAR) decreased to $7,6 \%$ when white blood cell count was high and USG findings were confirming appendicitis, whereas NAR was $46 \%$ in the patients who had normal white blood cell counts and normal USG findings (Figure 1).

Ultrasonography had a sensitivity of $71.6 \%$ and a specificity of $58 \%$. The predictive value of a positive test was $89 \%$ and the predictive value of a negative test was $30 \%$.

There was no statistically significant difference between the length of postoperative hospital stay for acute appendicitis and negative appendectomy group $(2.79+/-1.9$ and $2.66+/-1.7$ days, $\mathrm{p}>0.05)$

\section{Discussion}

Appendicitis is a very common disease with a lifetime occurrence of 7 percent [1]. Main symptom is right lower quadrant pain with anorexia and vomiting. Routine examination of a suspicious acute appendicitis patient consists complete blood count and urinalysis. The most important diagnostic tool is still physical examination but recently use of imaging studies is increasing day by day. This is a result of the need for early diagnose and treatment to achieve less perforation rate and complication [2].

In this study all 196 patients were demonstrating positive symptoms and physical signs for appendicitis. White blood cell counts were high for the $80 \%$ of the patients. Elangovan et al found high levels of white

Table 1 Negative appendicectomy rates

\begin{tabular}{cccc}
\hline & \multicolumn{2}{c}{ HISTOPATHOLOGY } & \\
& Negative & Positive & Total \\
\hline Male & $14(11.5 \%)$ & $108(88.5 \%)$ & $122(62.2 \%)$ \\
Female & $20(27 \%)$ & $54(73 \%)$ & $74(37.8 \%)$ \\
& & & $196(100 \%)$ \\
\hline
\end{tabular}

blood cell count in AA patients 80 percent [3]. Unfortunately, the white blood cell is elevated in up to 70 percent of patients with other causes of right lower quadrant pain [4]. NAR were $13.4 \%$ and $32.5 \%$ in the patients who had high and normal white blood cell counts, respectively.

We found our NAR as $17.3 \%$. Kyuseok et al studied 339 patients in two groups as preoperative no imaging and imaging studies and they found their NAR as 20.6 percent and 6.6 percent [5]. Hassan et al found, being younger than 21 years old, female gender, lower levels of polymorphonuclear leukocyt and lower heart rates as a risk factor for negative appendectomy [6]. Singhal et al showed 18.2 percent NAR for males and 48.2 for females at their study group [7]. Our NAR was 11.5 percent for male patients and 27 percent for females.

Radiology with the help of improving technology gets more space in the diagnose and differential diagnose for acute abdomen patients. We used USG for 196 suspicious acute appendicitis patient and found ultrasonography had a sensitivity of $71.6 \%$ and a specificity of $58 \%$. The predictive value of a positive test was $89 \%$ and the predictive value of a negative test was $30 \%$. Rajeev gave this ratios at his study on 118 preoperatively USG performed appendectomy patients as $63.3 \%, 82.14 \%$, 91.93\% and $41.07 \%$ [8]. Another study comparing 200 USG negative patients to 200 USG positive, NAR was found $4.7 \%$ for positive group [9]. Suma evaluated 1447 suspicious acute appendicitis patient with USG, 368 (25\%) were positive for appendicitis and 7 were false positive. Remaining 1079, 173 patients (12\%) had an other diagnose due to USG and 906 patients' complaints regressed during follow up. This study gave a sensitivity and specificity of $98 \%$ and $99 \%$. The predictive value of a positive and negative test were $98 \%$ and $99 \%$ with $\% 99$ overall diagnostic accuracy [10]. Difficulties with ultrasonography include identification of normal appendix to rule out acute appendicitis. Visualization of a normal appendix is more difficult in patients with a large body habitus and when there is an associated bowel obstruction, which causes overlying gas-filled loops of bowel. Accuracy of ultrasonography also decreases with retrocecal location of the appendix. Meckel's diverticulum, cecal diverticulitis, inflammatory bowel disease, pelvic inflammatory disease, and endometriosis can cause false-positive ultrasound results. Patients often complain of the pressure during evaluation. As seen above diagnostic value of USG can not be predictable, may be due to the experience of the radiologist, patient factors or technique used.

Today emergency service practitioners are using computerized tomography $(\mathrm{CT})$ for acute abdomen patients more and this may cause reduced rates of NAR. Motoki used $\mathrm{CT}$ for $\mathrm{AA}$ and published sensitivity and a 


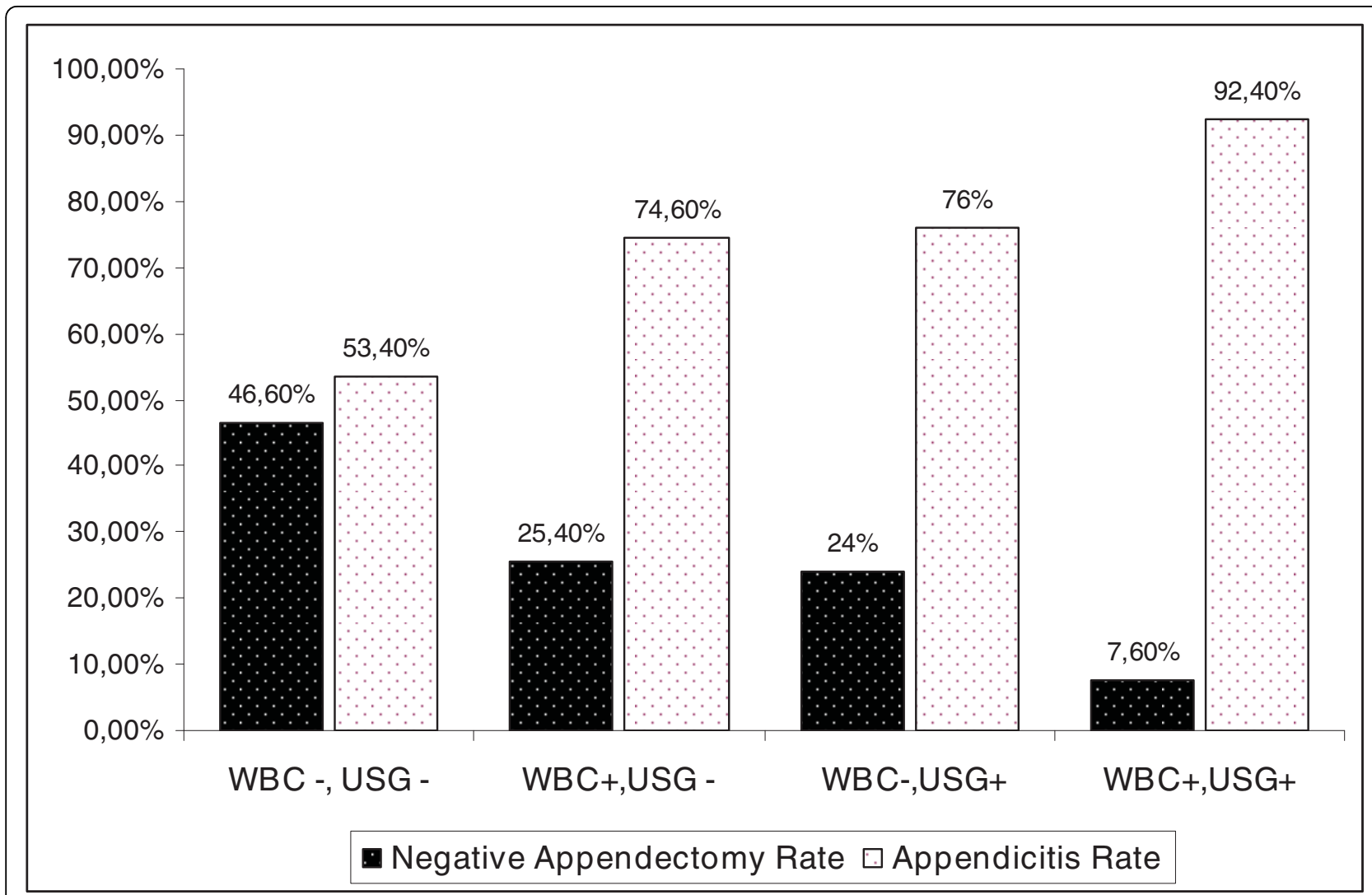

Figure 1 Percentage of negative appendicectomies and appendicitis through the patients due to WBC levels and USG findings.

specificity of $98.9 \%$ and $75 \%$, the predictive value of a positive test as $96 \%$ and negative test as 90\% [11]. Another CT technique uses rectal gastrografin lavmane. Advantages of this technique are, causing no delay for surgery due to oral intake, no need for intravenous contrast and ability to show not only inflamed appendix but also periappendicular inflammatory changes such as mesenteric edema [12,13].

Hannah et al analyzed the imagination studies as a factor of a delay in surgery and could not show any difference between non-imaging group and imaging group except a reduce of NAR from $10 \%$ to $3 \%$ favoring the latter [14]. Recent studies are showing short delays due to radiologic examinations have no bad effect on outcome for AA patients but they reduce NAR ratios $[15,16]$.

There were no statistically significant difference between the length of primary hospital stay for AA and NA group $(2.79+/-1.9$ and $2.66+/-1.7$ days, $\mathrm{p}>0.05)$. Kuzma showed no difference between complication rates for AA and NA groups [17]. Differences in the course for these two groups seem to be that NA patients re-admit emergency services more due to their unsolved problem although appendicitis patients meet more septic complications [18].

\section{Conclusions}

The diagnosis of appendicitis remains essentially clinical. Our NAR was 11.5 percent for male patients and 27 percent for females. Despite modern techniques, NA rates are still a problem for surgeons. If there is a doubt about the diagnose although leukocyte levels and ultrasonography results are normal, especially for female patients performing further radiologic examinations such as CT can be favorable.

\section{Abbreviations}

AA: acute appendicitis; NA: negative appendicectomy; NAR: negative appendicectomy rate; USG: ultrasonography; CT: computerized tomography.

\section{Authors' contributions}

KM and BK designed the study, collected and analyzed data. They drafted the manuscript.

MM and EO helped collecting the data, reviewing literature, statistical analyze and preparation of the manuscript

All authors have read and approved the main manuscript.

\section{Competing interests}

The authors declare that they have no competing interests.

Received: 2 February 2009

Accepted: 11 February 2010 Published: 11 February 2010 


\section{References}

1. Liu CD, McFadden DW: Acute abdomen and appendix. Surgery: scientific principles and practice Philadelphia: Lippincott-RavenGreenfield $\amalg$, et al , 2 1997, 1246-1261.

2. Wilcox RT, Traverso LW: Have the evaluation and treatment of acute appendicitis changed with new technology?. Surg Clin North Am 1997, 77:1355-1370

3. Elangovan S: Clinical and laboratory findings in acute appendicitis in the elderly. J Am Board Fam Pract 1996, 9:75-78.

4. Calder JD, Gajraj H: Recent advances in the diagnosis and treatment of acute appendicitis. Br J Hosp Med 1995, 54:129-133.

5. Kim K, Lee CC, Song KJ, Kim W, Suh G, Singer AJ: The impact of helical computed tomography on the negative appendectomy rate: a multicenter comparison. Journal of Emergency Medicine 2008, 34:3-6.

6. Hassan AM, Shaban M, Mohsen TK, Ali K, Yashar M: Predicting negative appendectomy by using demographic, clinical, and laboratory parameters: A cross-sectional study. International Journal of Surgery 2008, 6:115-118.

7. Singhal V, Jadhav $V$ : Acute appendicitis: are we over diagnosing it?. Annals of The Royal College of Surgeons of England 2007, 89:766-769.

8. Rajeev S, Kasliwal DK, Sharma RG: Evaluation of negative appendicectomy rate in cases of suspected acute appendicitis and to study the usefulness of ultrasonography in improving the diagnostic accuracy. Indian Journal of Surgery 2007, 69:194-197.

9. Mardan MA, Mufti TS, Khattak IU, Chilkunda N, Alshayeb AA, Mohammad AM, ur Rehman Z: Role of ultrasound in acute appendicitis. J Ayub Med Coll Abbottabad 2007, 19:72-79.

10. Summa M, Perrone F, Priora F, Testa S, Quarati R, Spinoglio G: Integrated clinical-ultrasonographic diagnosis in acute appendicitis. Journal of Ultrasound 2007, 10:175-178.

11. Kaidu M, Oyamatu M, Sato K, Saitou A, Yamamoto S, Yoshimura N, Sasai K: Diagnostic limitations of $10 \mathrm{~mm}$ thickness single-slice computed tomography for patients with suspected appendicitis. Radiation Medicine 2008, 26:63-69.

12. Gupta $H$, Dupuy DE: Advances in imaging of the acute abdomen. Surg Clin North Am 1997, 77:1245-1263.

13. Paulman AA, Huebner DM, Forrest TS: Sonography in the diagnosis of acute appendicitis. Am Fam Physician 1991, 44:465-8.

14. Hannah G, Piper MD, Rusnak C, Orrom W, Hayashi A, Cunningham J: Current management of appendicitis at a community center-how can we improve?. The American Journal of Surgery 2008, 195:585-589.

15. Clyde C, Bax T, Merg A, MacFarlane M, Lin P, Beyersdorf S, McNevin MS: Timing of intervention does not affect outcome in acute appendicitis in a large community practice. The American Journal of Surgery 2008, 195:590-593.

16. Guss DA, Behling CA, Munassi D: Impact of Abdominal Helical Computed Tomography on the Rate of Negative Appendicitis. Journal of Emergency Medicine 2008, 34:7-11.

17. Kuzma J: Randomized clinical trial to compare the length of hospital stay and morbidity for early feeding with opioid-sparing analgesia versus traditional care after open appendectomy. Clinical Nutrition 2008, 27:694-699.

18. Simpson J, Samaraweera APR, Sara RK, Lobo DN: Acute appendicitis - a benign disease?. Annals of The Royal College of Surgeons of England 2008, 90:313-316.

\section{Submit your next manuscript to BioMed Central and take full advantage of:}

- Convenient online submission

- Thorough peer review

- No space constraints or color figure charges

- Immediate publication on acceptance

- Inclusion in PubMed, CAS, Scopus and Google Scholar

- Research which is freely available for redistribution

Submit your manuscript at www.biomedcentral.com/submit
Biomed Central 